\title{
Sustainability and the Canadian Forest Sector
}

Sten Nilsson (nilsson@iiasa.ac.at)

Michael Gluck (michael.gluck@mnr.gov.on.ca)

\section{Approved by}

Gordon J. MacDonald

Director, IIASA

9 August 2000 Institute, its National Member Organizations, or other organizations supporting the work. 


\section{Contents}

1 INTRODUCTION 1

1.1 Our Interpretation of the Meaning of Sustainability
and the Forest Sector

1.2 Sustainability in an Evolving Process 2

$\begin{array}{lr}1.3 \text { Consequences } & 2\end{array}$

2 HOW ARE WE TRYING TO SOLVE SUSTAINABILITY TODAY? 3

3 SCALE IMPACTS: LOOKING OUTSIDE CANADA 7

$\begin{array}{lll}3.1 & \text { Information Technology and Substitution } & 7\end{array}$

$\begin{array}{ll}3.2 & \text { Reallocation of the Forest Industry } \\ \end{array}$

3.2.1 Wood Costs 11

\begin{tabular}{ll}
3.2 .2 & Plantation Forests \\
\hline
\end{tabular}

$\begin{array}{ll}3.3 & \text { International Agreements } \\ \end{array}$

$\begin{array}{ll}3.4 \text { Post Mortem } & 16\end{array}$

4 CRITERIA AND INDICATORS AND THE FOREST PLANNING PROCESS FROM NATIONAL TO LOCAL LEVELS: A CASE STUDY 16

$\begin{array}{ll}\text { 4.1 The Institutional/Legislative Framework } & 18\end{array}$

4.2 Planning Direction - What is the Future Forest Condition? 19

4.2.1 National Level 19

4.2.2 Provincial Level — The Case of Ontario 19

$\begin{array}{lll}4.2 .3 & \text { Local Level } & 20\end{array}$

4.3 Evaluating Sustainability $\quad 21$

4.3.1 Conflicts between Criteria and Indicators 22

5 ANALYTICAL SUPPORT: INFORMATION COLLECTION AND DISTRIBUTION 24

6 WHAT TO DO? 25

$\begin{array}{lr}\text { REFERENCES } & 27\end{array}$ 


\section{Abstract}

This paper was presented as a keynote address at the conference on Forest Sustainability - Beyond 2000 held in May 2000 in Thunder Bay, Canada. The conference brought together forest sector leaders and professionals from across Canada.

This paper is an extension of earlier work on the sustainability of North American wood supplies (Nilsson et al., 2000). The present paper examines the efficiency of the current established criteria and indicators for sustainable development of the forest sector. The current system of criteria and indicators concentrates on the management aspects instead of the objectives setting. The current system is too complicated to be implemented and neglects the fact that sustainability cannot be achieved by a top-down approach but only by the people working on the ground at the local level. This paper presents a number of guidelines on the necessary steps to be taken in order to move towards A Forest Sector for Sustainable Development. 


\section{About the Authors}

Sten Nilsson is Counselor the Director and Leader of the Forestry Project at IIASA. Michael Gluck was a research scholar in the Forestry Project until mid-July 2000 and is now with the Ontario Ministry of Natural Resources, Canada. 


\title{
Sustainability and the Canadian Forest Sector
}

\author{
Sten Nilsson and Michael Gluck
}

\section{Introduction}

After checking several library indexes and the Internet, we have identified that there are some 75,000 titles available that address sustainability and the forest sector. This fact alone would be reason enough to turn down any invitation to discuss the issue of sustainability and the forest sector of any kind. But having accepted to address this issue we will try to do our best. Given the magnitude of existing opinions on and interpretations of sustainability there is no way to present any consensus on the issue. However, to make a presentation meaningful, we will declare up front our view on sustainability and the forest sector.

\subsection{Our Interpretation of the Meaning of Sustainability and the Forest Sector}

At the 1992 United Nations Conference on Environment and Development, a number of forest principles were stated of which one was the following:

- The subject of forests is related to the entire range of environmental and development issues and opportunities, including the right to socioeconomic development on a sustainable basis.

Nilsson (1991), Seip (1996), and Duinker et al. (1998) discuss three concepts of sustainability:

- sustainable management of forest resource use;

- sustainable development of forest resource use; and

- forestry for sustainable development.

The first concept is an old one, concentrating on the maintenance of supply of forest products, although not considering issues external to the forest and forestry itself. The second deals with deforestation, forest cover, forest quality, etc., but is also disconnected from ongoing transitions in a changing world.

The third concept encompasses all human requirements, with the goal of increasing human welfare and aggregated benefits from the forests. This concept implies that the production of wood, the maintenance of biodiversity, the sequestration of greenhouse gases, etc., are means and not objectives, with human welfare being the overall objective. This corresponds with FAO's Strategic Plan for Forestry (FAO, 1997), the aim of which is "to enhance human wellbeing through the sustainable management of the world's trees and forests". The Canadian Standards Association (CSA, 1996) states that sustainable forest management is 
"management to maintain and enhance the long-term health of forest ecosystems, while providing ecological, economic, social and cultural opportunities for the benefit of present and future generations".

Thus, our interpretation is that we should aim at Forestry or a Forest Sector for Sustainable Development, with human welfare being the overall objective and supply of wood, non-wood benefits, ecological and social functions being means to achieve this objective.

\subsection{Sustainability in an Evolving Process}

Sustainability is a "new" aspect of long-term thinking in the forest sector. Long-term thinking has been a fundamental element of forestry in many countries. However, the concepts and goals underlying this long-term thinking have evolved over time, due to many factors, such as changing societal values, changed economic conditions, population growth, etc. The sustainability concept is going and will go through the same dynamic evolving process, which depends on global, international, national, regional and local developments. Each period of time has its own counsels with respect to the management of the forest sector (Kardell, 1995).

\subsection{Consequences}

In order to achieve a forest sector for sustainable development with the goal of improving human welfare we have to address all aspects of human welfare across temporal and spatial aspects that we can manage through our use of natural resources. We think this is what every stakeholder of the forest sector, independent of their affiliation to political, professional, environmental, and other interest groups, would like to support. This can be illustrated by a simplified matrix in which a set of indicators is used to evaluate achievement of goals for a specific set of values for a specific geography (management unit, region, country, etc.) and time (tactical to strategic) (Figure 1).

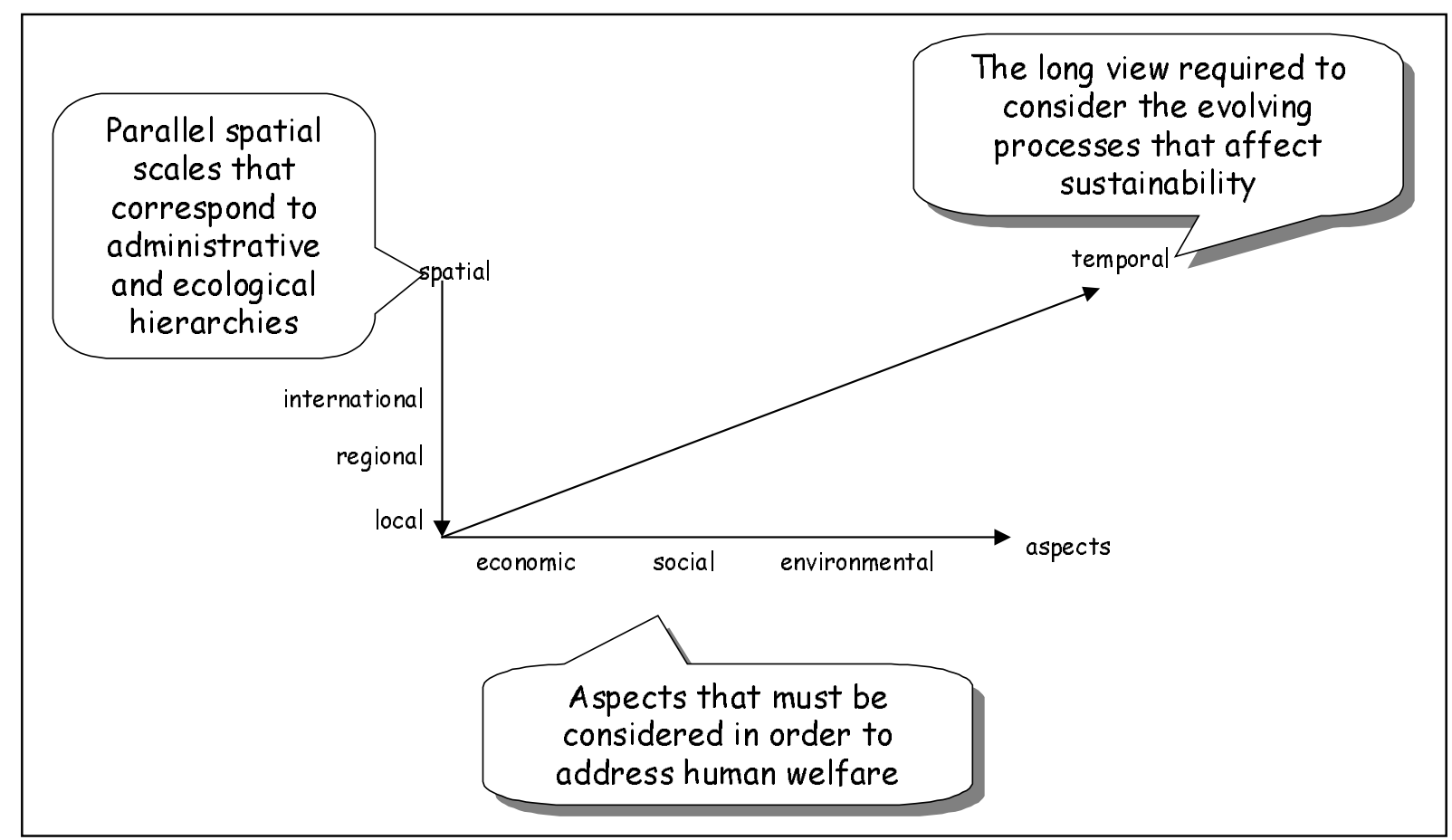

Figure 1: Three dimensions of thinking about sustainability. 
In this concept, the evaluation of sustainability considers the impact of management activities equally across human welfare aspects. These criteria are also considered not only locally for current time scales but "nested" across management scales (international, regional, local) and temporal (annual, mid-term and long-term). Thus, we must operate with a three-dimensional approach in which there is a strong interaction and trade-off between the different spatial levels and the different aspects of sustainability, all of which is influenced by time.

One conclusion from the simplified Figure 1 is obvious; sustainability cannot be achieved by working with one or a few segments of the matrix. It is also obvious that fulfilling all aspects of sustainability, at all spatial levels and at all times is a difficult task and is the platform for conflicts among stakeholders of the forest sector.

\section{How Are We Trying to Solve Sustainability Today?}

The way in which we are trying to solve the problems outlined in Figure 1 is to try and gain a consensus amongst the stakeholders at an international level on how to manage the forest sector in the form of binding or non-binding international agreements. These agreements must be implemented at the local level in order to achieve sustainability. The most concrete result of this approach is the development of criteria and indicators for temperate and boreal forests through the so-called Montreal and Helsinki Processes. The basic idea is that by monitoring these indicators the degree of sustainability can be measured. A further step in this direction is certification. Roughly defined, certification is the process of establishing whether or not a particular forest area is achieving its objectives based upon criteria and indicators of sustainable forest management.

Is this the right approach for achieving A Forest Sector for Sustainable Development? We doubt it. We would like to link the criteria and indicators approach to the concept we presented in Figure 1. This linkage is simplified in Figure 2. 


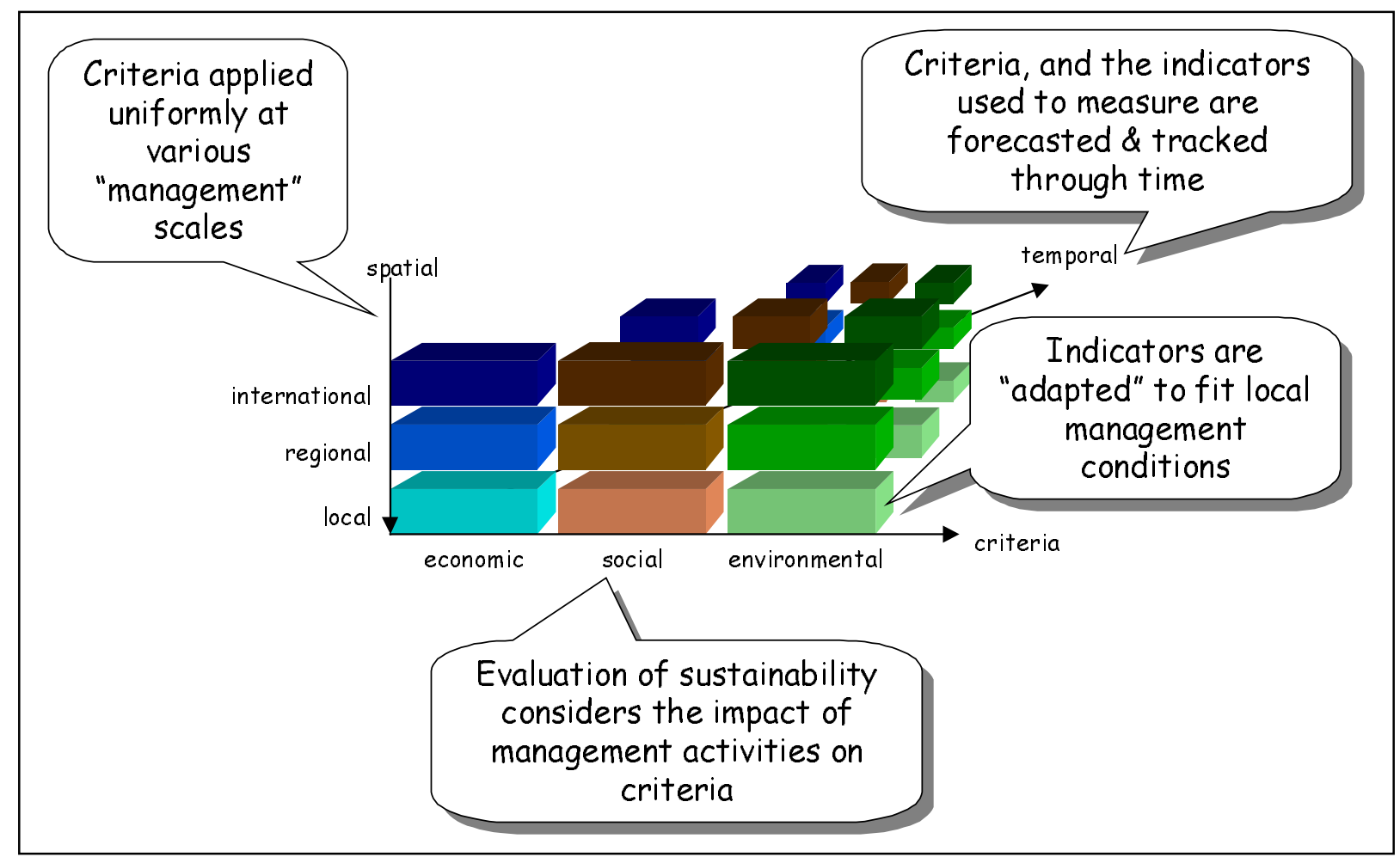

Figure 2: Three dimensions of sustainability in relation to the criteria and indicators framework.

This links back to our earlier problem identification with the sustainability concept and the criteria and indicator approach by Nilsson (2000a) based on Heilig (1997). A summary of this critique is presented in the following text box. 
What is environmentally sound may not be acceptable for our social structure, our economy or our culture. A most serious obstacle to a universal concept is the fact that human life has to be dealt with more than one dimension. Stability of our ecosystems is only one of many concerns.

The concept is based on social concept of harmony and ignores the fact that conflicts and fierce competition drive human development. The whole evolution of the human species indicates that we are part of the ecosystems (Behan, 1997), but we are not just happy being part of a sustainable ecosystem. We want to dominate and grow. Through all kinds of interventions, we try to shape our environment for our benefit - even if at the cost of other species and our human neighbor. We are, by nature, a competitive animal.

It can be demonstrated that a strategy of simple-minded cooperation will always lose in an environment where the other players can gain a slight advantage by not cooperating (Nowak et al., 1995). Human interaction is based on bargaining, open threats, economic pressure, coercion, or a strategy of limited retaliation against noncooperation. This diplomacy of violence (Schelling, 1966) is one of the fundamental principles of all social, economic and political development, which is neglected in the current concept. This is especially crucial at a time when the world is swept by, globalization.

The concept reduces the analysis of social, economic, cultural and political processes to a simplistic Bio-Physical Framework. It has been demonstrated that the most important social processes are not at all similar to those in ecosystems (Etzioni, 1968).

Thus, we do not think that we can achieve A Forest Sector for Sustainable Development by merely implementing the currently accepted criteria and indicators and by the connected certification, due to the fact that the current concept does not address the fundamental social problem of power imbalance between societies and social groups and does not identify which social, economic and political structures and processes a society should use in order to promote sustainable development.

The concept of criteria and indicators ignores the fundamental diversity of interests. One of the major characteristics of our world is that people fundamentally disagree about objectives, values and lifestyles.

It can be concluded that the current set up of the criteria and indicators' approach cause a number of problems, which are difficult to handle (Figure 3). The decision of values represented by the criteria is not easy to categorize; the majority of the indicators focus on biological aspects of environment (Figure 4) and the top-down approach of criteria limits sustainable solutions (in a wide sense) at local scales. This is probably a result of resource managers feeling more comfortable dealing with natural systems rather than socioeconomic ones. A way to address this inequity might be to include socioeconomic experts in the evaluation process. 


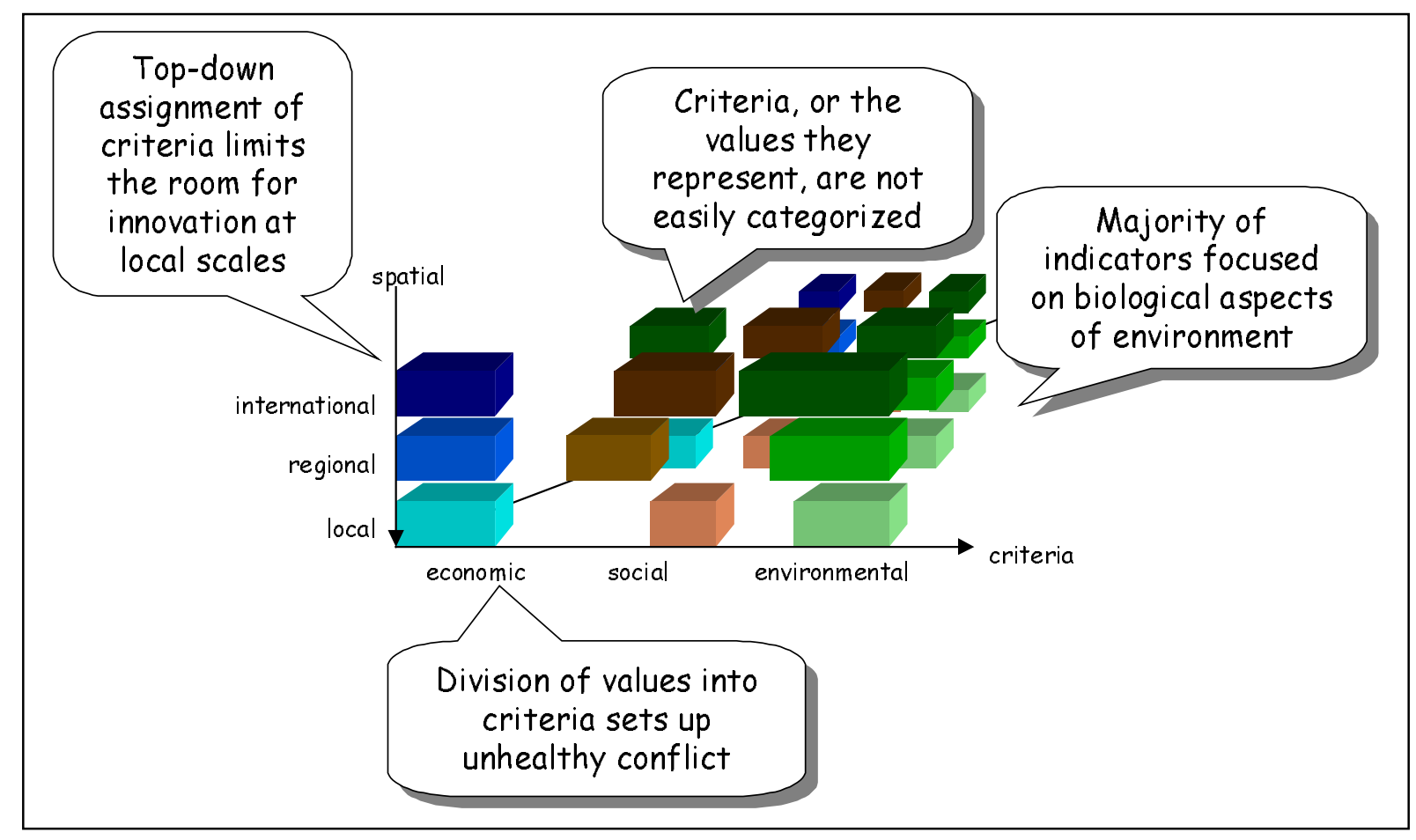

Figure 3: Problems with the current approach to criteria and indicators.

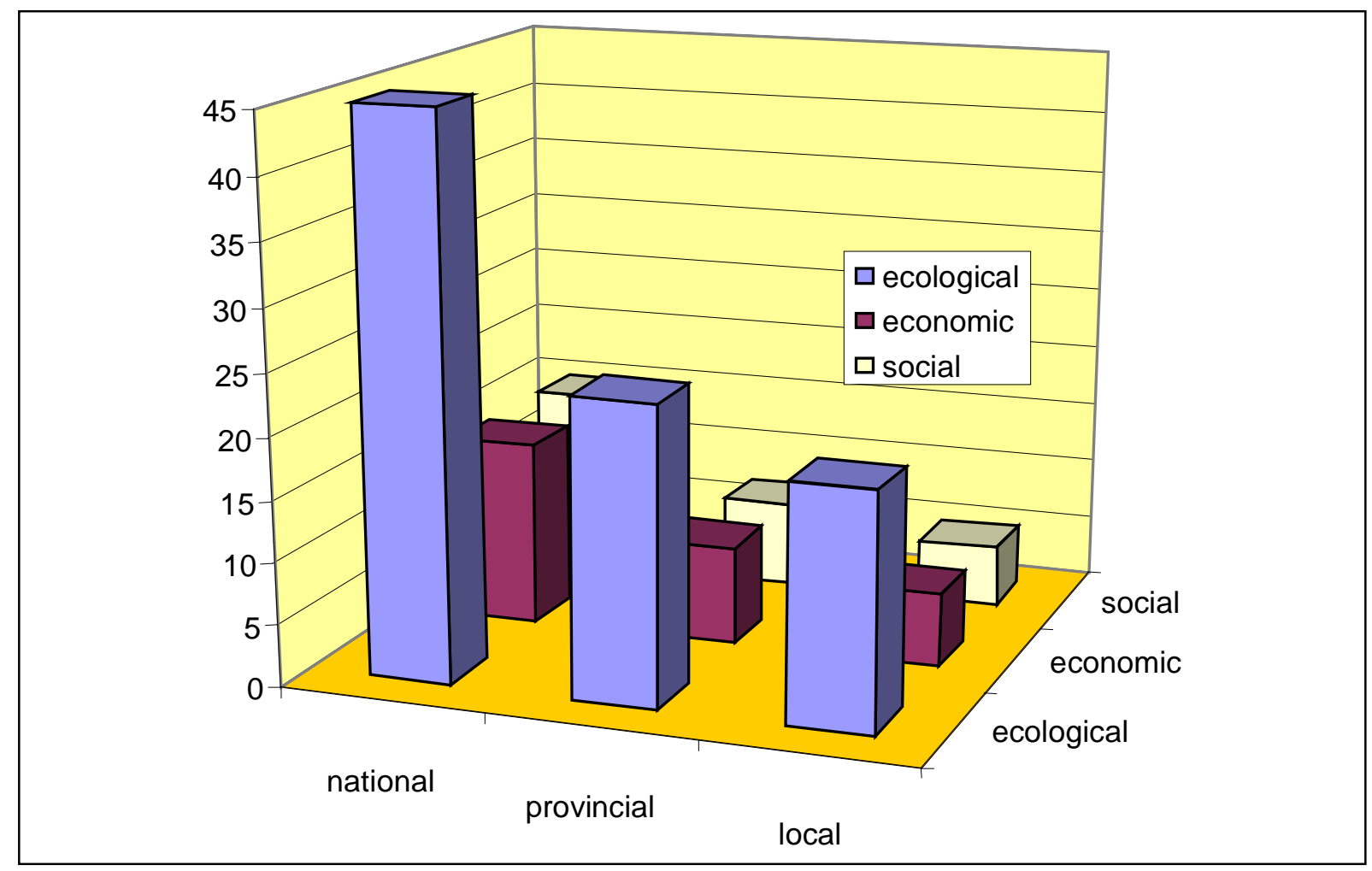

Figure 4: Number of indicators of sustainability (grouped into ecological, economic and social aspects) applied across Canada's national, provincial and local management scales. 
In addition, it can be concluded that the current approach of criteria and indicators is static and does not take into account that the sustainability issue is an evolving process and by that largely neglects the temporal aspects illustrated in Figure 1. This is, in part, due to shortcomings in the institutional framework, which we will discuss later.

\section{Scale Impacts: Looking Outside Canada}

The current Criteria and Indicator framework is set at the national level but should be implemented at the local level. Part of this implementation includes adapting indicators to local conditions - in reality, however, the same indicator set is commonly applied. But their concept does not take into account that the development of the forest sectors changes paths very rapidly due to the international development, such as the globalization of the forest sector. It means that the scale impacts and the temporal aspects are to a large extent neglected in the current concept. That brings us to the question on what international developments must Canada take into account in the sustainability debate? We will try to illustrate a few such issues.

\subsection{Information Technology and Substitution}

There is substantial substitution occurring in the lumber sector. The development of engineered wood goes rapidly, which means the exchange of high to low quality wood. In the scenarios presented in the following paragraphs with respect to lumber and panels, we have taken into account the U.S. development (Fleishman et al., 1999) in order to illustrate possible developments by using Ontario as an example.

The development of Information Technology is dramatic and no one knows how much it will influence the forest sector in the form of business environment and consumption of different forest products. However, one thing is certain; the future of the forest sector will be much different than the past due to information technology and change will come at an everincreasing rate (McIntyre, 2000).

We have recently started to work on these issues at IIASA (Obersteiner and Nilsson, 2000). In order to illustrate possible effects of the Information Technology with respect to demand on the paper group "Newsprint and Uncoated Printing Papers" and "Other Paper Grades" and its implications for Ontario, we have used a model taking into account the following factors:

- Demographic development by age, gender and education;

- Readership rate by age classes and readership of paper copies;

- Reading intensity by educational class;

- Amount of information in society through printed matter;

- Economic wealth;

- Number of pages and size of printed publications; and

- Grammage.

The different scenarios taking substitution and information technology into account for Ontario are presented in Figures 5-8. It can be concluded that there are rather large differences in the developmental path in the different scenarios. Depending on the development the performance of the criteria and indicators will vary largely. We have tried to 
illustrate this in Table 1 for some of the indicators by using the high and low scenarios for different forest products.

The different developments will heavily influence the performance of the current indicators. It means that the international development may largely wipe out efforts at the local level to achieve "good indicators on sustainable development".

In addition, based on basic data from Price Waterhouse Coopers (1999) on Ontario we have tried to assess the difference in the overall outcome of the Ontario forest sector between the high and low scenarios. The difference is rather dramatic:
Net earnings
$65 \%$
Payments to Governments
900 million $\$(1998 \$)$
Direct and Indirect Employment
105,000 person years.

We would argue that value setting by the society will be quite different between the high and low scenarios and that the indicators will have a certain meaning and value in the high scenario situation, but quite different ones in the low scenario.

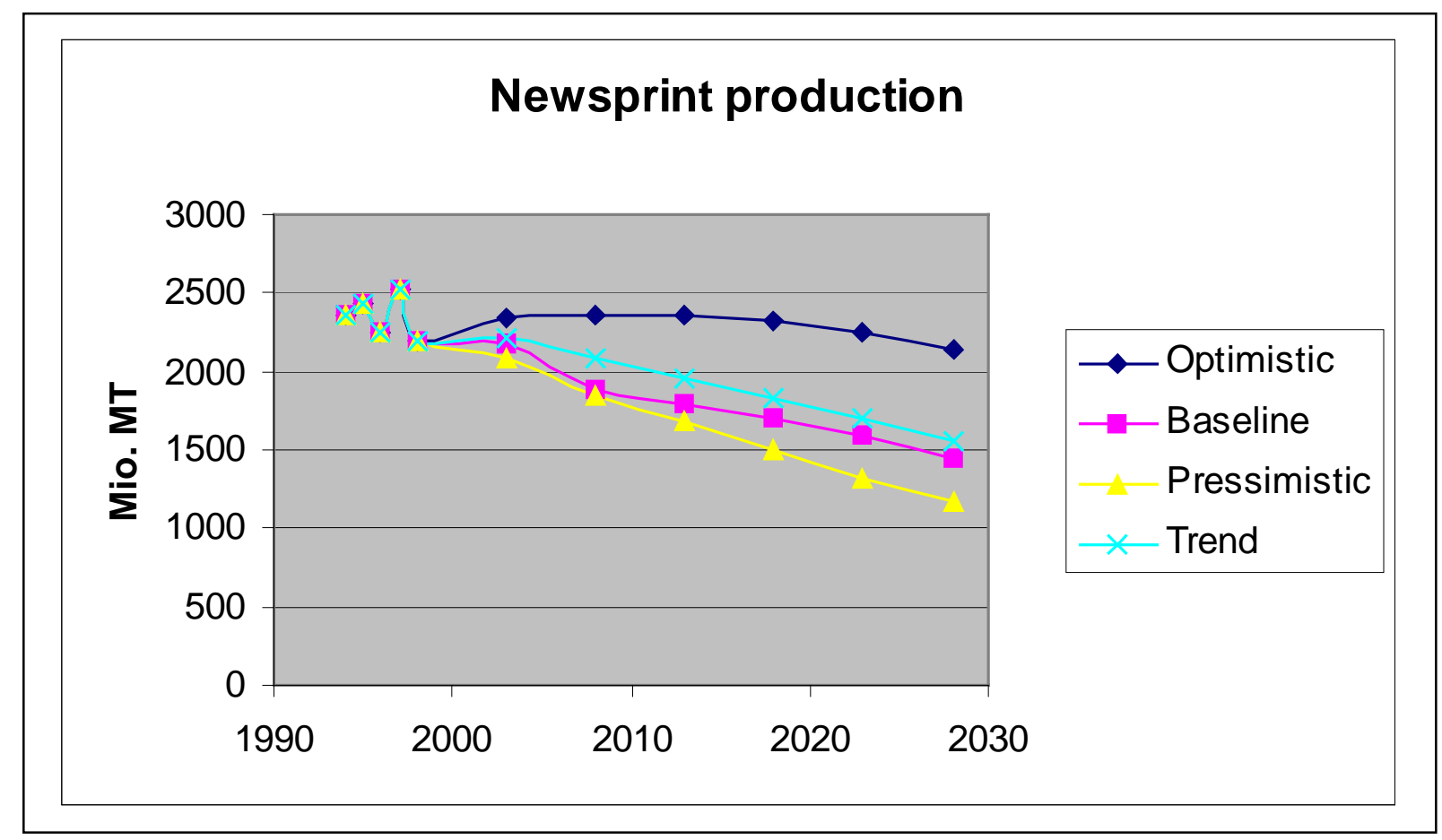

Figure 5: Newsprint production scenarios for Ontario. 


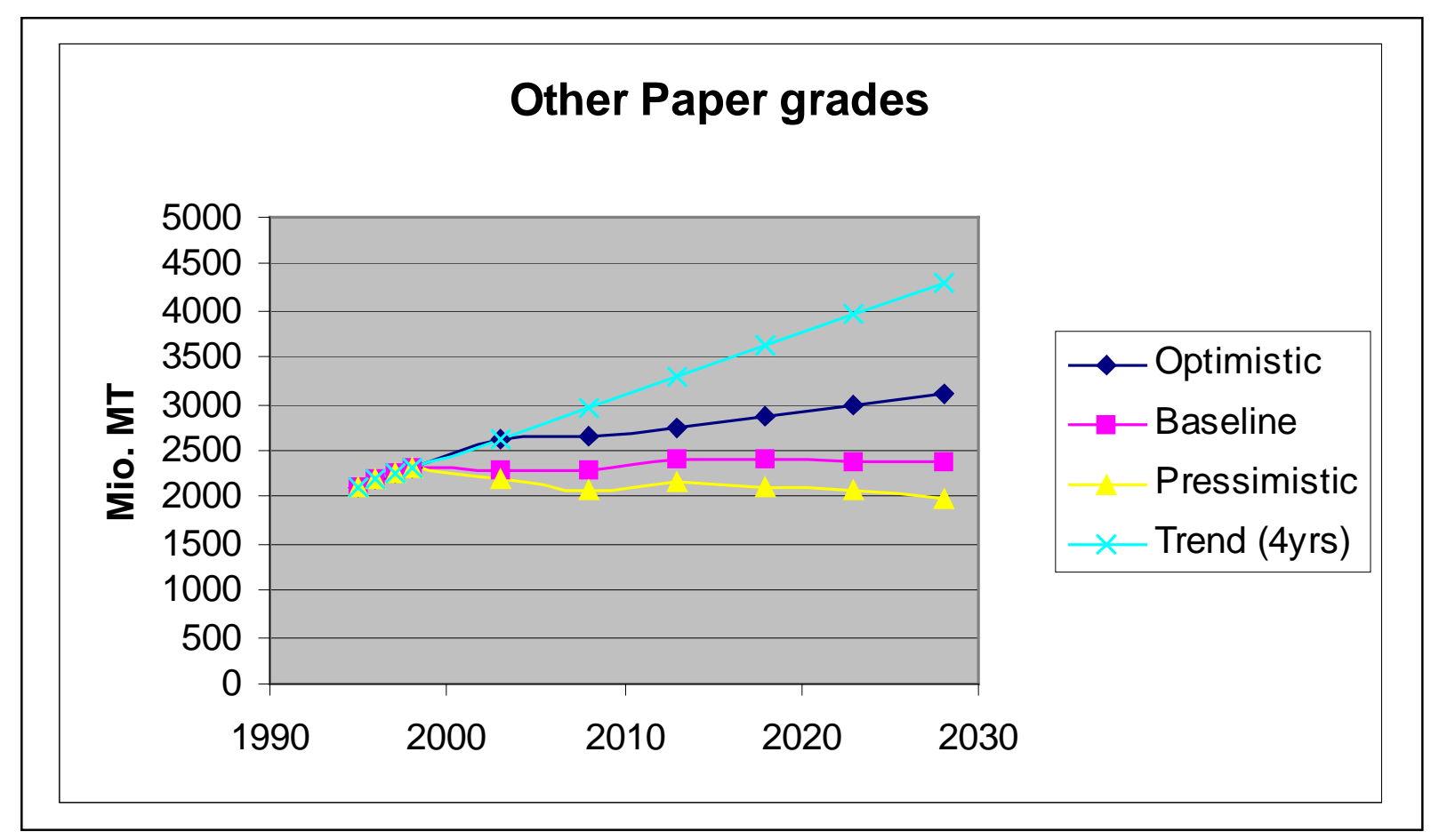

Figure 6: Other paper grades production scenarios for Ontario.

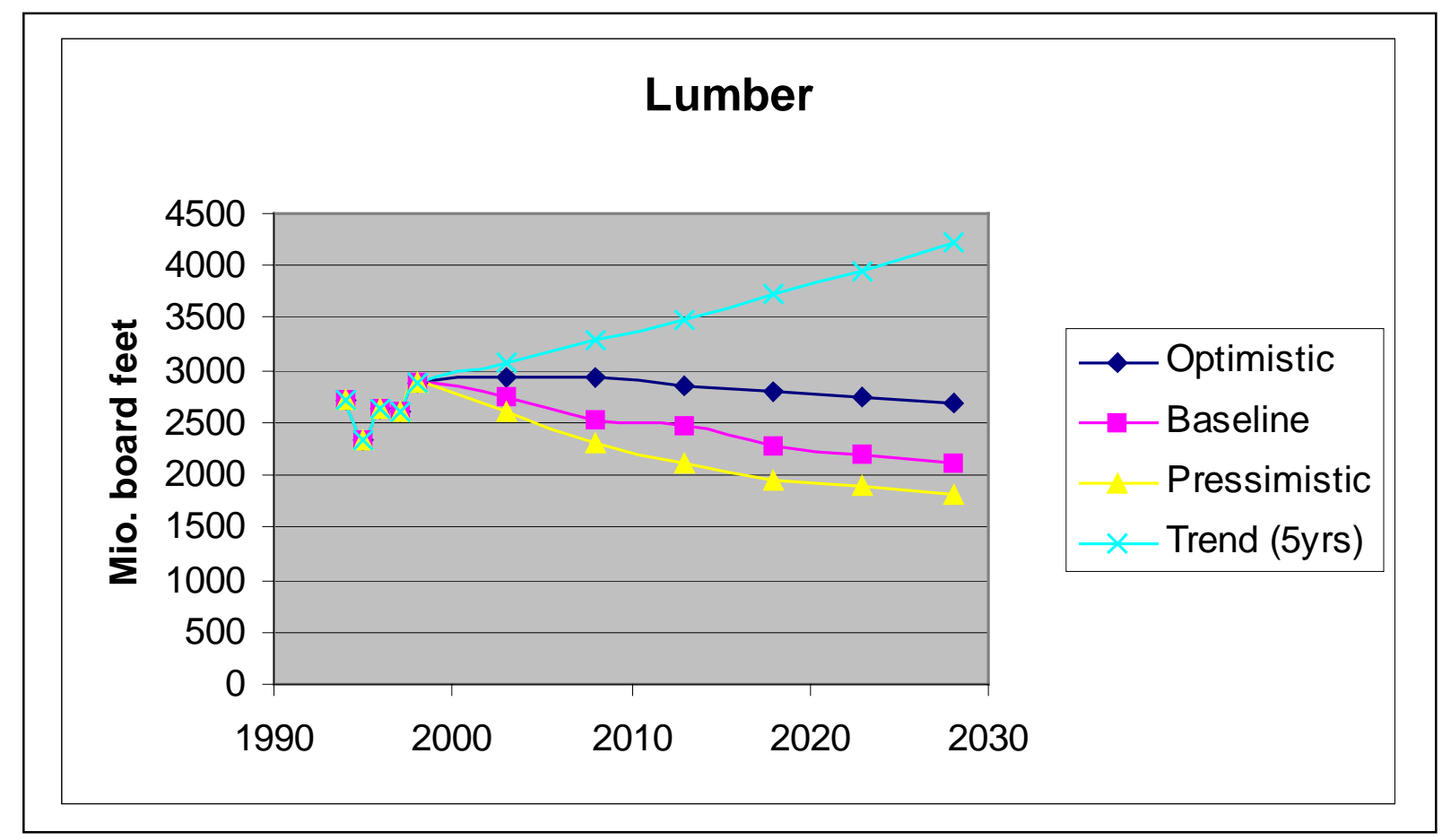

Figure 7: Lumber production scenarios for Ontario. 


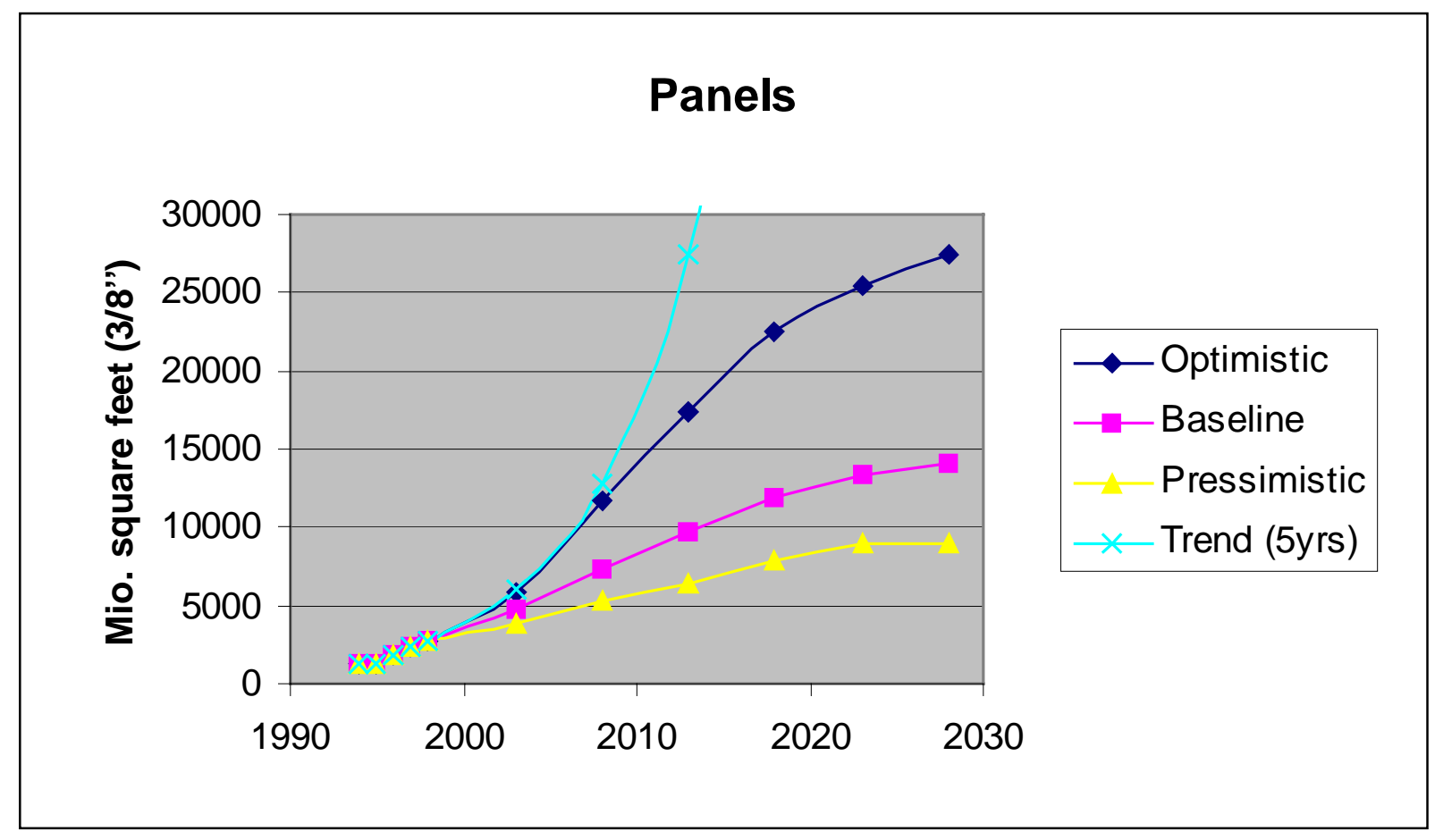

Figure 8: Panel production scenarios for Ontario.

Table 1: Changes in sustainability indicators relative to forest industry trends.

\begin{tabular}{|c|c|c|c|c|c|c|}
\hline \multirow{2}{*}{$\begin{array}{l}\text { INDICATOR } \\
\text { SCENARIO }\end{array}$} & \multicolumn{2}{|c|}{ Lumber } & \multicolumn{2}{|c|}{ Panels } & \multicolumn{2}{|c|}{$\begin{array}{l}\text { Newsprint/Uncoated } \\
\text { Paper Products }\end{array}$} \\
\hline & low & high & low & high & low & high \\
\hline ecosystem fragmentation & Improved & decreased & status quo & decreased & improved & status quo \\
\hline RTE species & Improved & decreased & status quo & decreased & improved & status quo \\
\hline forest diversity & Improved & decreased & status quo & decreased & improved & status quo \\
\hline wildlife populations & Improved & decreased & status quo & decreased & improved & status quo \\
\hline natural disturbances & Increased & decreased & status quo & decreased & increased & status quo \\
\hline forest growing stock & Increased & decreased & status quo & decreased & increased & status quo \\
\hline wood supply & Decreased & increased & status quo & decreased & decreased & status quo \\
\hline $\begin{array}{l}\text { commercial value of } \\
\text { selected species }\end{array}$ & Decreased & increased & status quo & decreased & decreased & status quo \\
\hline $\begin{array}{l}\text { capital expenditure in } \\
\text { resource-based } \\
\text { businesses }\end{array}$ & Decreased $^{1}$ & increased & status quo & decreased $^{1}$ & decreased & status quo \\
\hline employment by the sector & Decreased & increased & status quo & increased & decreased & status quo \\
\hline $\begin{array}{l}\text { population in forest-based } \\
\text { communities }\end{array}$ & Decreased & increased & status quo & increased & decreased & status quo \\
\hline GDP value-added & Decreased $^{1}$ & increased & status quo & increased $^{1}$ & decreased & status quo \\
\hline
\end{tabular}

\footnotetext{
${ }^{1}$ There is a strong linkage between high panel production and low lumber production. A higher panel production means a higher use of low quality wood and less people employed
} 


\subsection{Reallocation of the Forest Industry}

Earlier we brought up the fact that substitution of products with high quality wood to products using low quality wood through engineered wood is expected. This means that the industry does not depend on high quality wood (boreal forests) any longer as the industry creates the high quality in the factories through new technologies. For example, New Zealand has stopped its famous pruning program in the plantations as factories can produce high quality wood more efficiently than nature. It means that factories will use more low quality wood, which can be produced inexpensively. We have also pointed out that traditional wood products cannot compete with cheaper alternative materials resulting in substitution. Also, the fastest growing markets for forest products are foreseen in the Southern Hemisphere. All of this drives the future allocation of the industry to locations with cheap wood production and with the fastest growing markets. This will create a problem for the Canadian forest industry. Let us demonstrate a few developments.

\subsubsection{Wood Costs}

Bull (2000) and Spears (2000) illustrate that the industrial wood costs from the natural forests in Canada have escalated during the 1990s triggering significant adjustments in the forest industry (Figure 9). Both authors identify increasing difficulties for the Canadian industry to compete with lower wood costs from intensively managed forests. With a continuing development like this Canada will cost itself out of the international market.

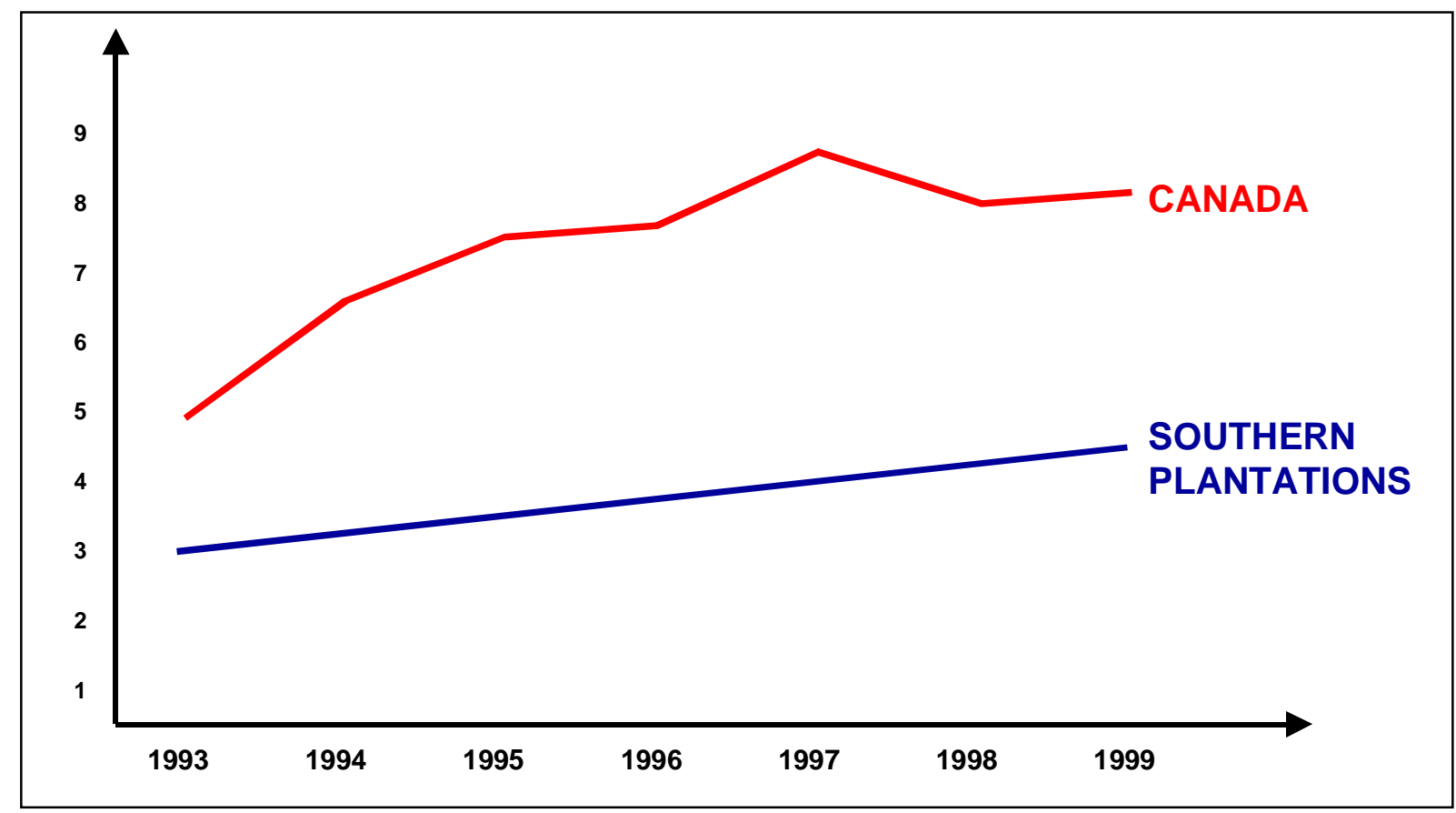

Figure 9: Relative delivered wood costs, Canada versus Southern plantations. 


\subsubsection{Plantation Forests}

At the same time there has been rapid development of industrial plantations in the world. Brown (1999) and Whiteman and Brown (1999) estimate the industrial plantation area to be 103 million hectares and the non-industrial plantation area to be 20 million hectares in 1995 . Overall, $54 \%$ of the industrial plantations are assessed to be less than 15 years and nearly $25 \%$ to be established in the past 5 years, which is largely a result of the accelerated rate of establishments of new plantations. The establishment of new plantations is assumed to continue to increase (Table 2) according to Brown (1999).

Table 2: Industrial forest plantation development scenarios.

\begin{tabular}{lrcc}
\hline Geographic Area & $\begin{array}{c}\text { Area, } \\
\mathbf{1 9 9 5}\end{array}$ & $\begin{array}{c}\text { Area Scenario A, } \\
\mathbf{2 0 5 0}\end{array}$ & $\begin{array}{c}\text { Area Scenario B, } \\
\mathbf{2 0 5 0}\end{array}$ \\
\hline North and Central America & 18.9 & 29.3 & 43.2 \\
United States & 18.4 & 28.5 & 41.2 \\
South America & 5.4 & 8.4 & 13.6 \\
Asia & 41.8 & 64.8 & 119.5 \\
China & 17.5 & 27.1 & 68.3 \\
India & 4.1 & 6.4 & 11.7 \\
Japan & 10.7 & 16.6 & 12.4 \\
Oceania & 2.7 & 4.2 & 5.7 \\
Africa & 3.6 & 5.6 & 8.9 \\
Europe & 8.7 & 13.5 & 15.3 \\
Former USSR & 22.2 & 34.4 & 28 \\
Russian Federation & 17.1 & 26.5 & 21.1 \\
\hline WORLD & 103.3 & 160.2 & 234.2 \\
\hline
\end{tabular}

The scenarios produced by Brown (1999) imply that 180 million hectares could sustainably supply the world with some 1500 million $\mathrm{m}^{3}$ around 2030. This is in line with assessments made by Hagler (1999) and Bazett (2000). This corresponds to an industrial wood supply from plantations of around 45\% in 2030 compared to $22 \%$ in 1997.

It is also of importance to point out that during the 1990s it could be seen that a major policy change in one country triggered the plantation establishments in other countries.

Hagler (1999) suggests that all of the industrial roundwood supply today is being derived from an area of about 600 million hectares, i.e., about $20 \%$ of the global closed forest area. This together with the potentials from the plantations have triggered Spears (2000) to come up with the vision that in the future the world could be supplied with industrial roundwood from $20 \%$ of its closed forests with intensive management and the remaining $80 \%$ of the forests should be more or less managed for local community needs, biodiversity, wildlife, water protection, reservation, etc. This is the so-called 20/80 ratio (Figure 10). However, policies for the management of $80 \%$ of the forests allocated for management of utilities other than wood are unclear and the funding of this management is unknown. 


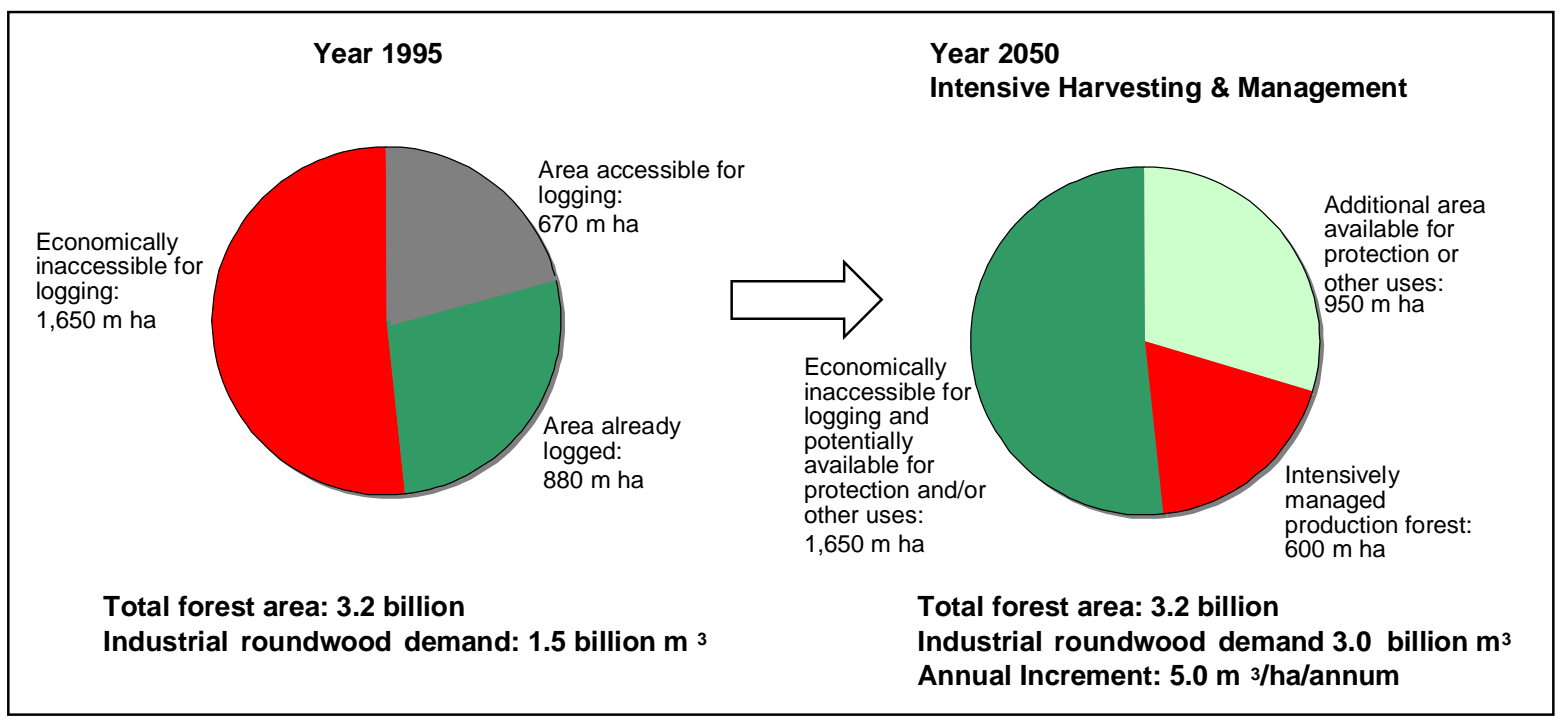

Figure 10: Industrial roundwood supply and demand scenario for the year 2050.

(Source: After Spears, 2000).

Based on the above, it is obvious that Canada must develop a new overall strategy based on the international development in order to be able to contribute to sustainable development.

Binkley (1997) advocates zoning and intensively managed plantations, which would preserve nature. He uses an example from British Columbia stating that $18 \%$ of the land area could be used for intensive forest management practices and the yields could be increased by a factor of two or three compared to natural forests. Oliver (1999) is critical to the zoning of forest production into intensively managed plantations, and integrated management and reserves from ecological, social and political points of view. He advocates the application of integrated management. We are not in the position to argue what is right or wrong but we could argue that there is a strong need that a clear and consistent policy emerges in Canada on this issue and that this policy will heavily influence the current system of criteria and indicators. If the Oliver concept of integrated management is used we could argue that in our example of Ontario the forest sector would shrink by at least $25 \%$ by 2030 . We have used the same indicators as in Table 1 to illustrate the impacts of a possible overall changed Canada Forest Sector Policy (Table 3). 
Table 3. Changes in sustainability indicators relative to land use allocation.

\begin{tabular}{l|l|c}
\hline INDICATOR & $\begin{array}{c}\text { Zoning Intensively } \\
\text { Managed Resources }\end{array}$ & $\begin{array}{c}\text { Integrated } \\
\text { Management }\end{array}$ \\
\hline ecosystem fragmentation & & improved \\
\hline RTE species & & improved \\
forest diversity & improved \\
\hline wildlife populations & $\begin{array}{l}\text { The current C\&I } \\
\text { framework can } \\
\text { probably not be applied } \\
\text { equally to all types of }\end{array}$ & $\begin{array}{l}\text { improved } \\
\text { natural disturbances }\end{array}$ \\
\hline forest growing stock & $\begin{array}{l}\text { management, multiple } \\
\text { use, protection, etc.) or }\end{array}$ & ??? \\
\hline wood supply & will require different \\
Commercial value of selected species & decreased \\
\hline $\begin{array}{l}\text { capital expenditure in resource-based } \\
\text { businesses }\end{array}$ & & decreased \\
\hline Employment by the sector & & decreased \\
\hline population in forest-based communities & & decreased \\
\hline GDP value-added & & decreased \\
\hline
\end{tabular}

From this example, we can draw the following conclusions:

- The possibilities to improve the indicators on sustainability at the national and local scales are heavily dependent on international development.

- There is limited use of implementing criteria and indicators at the local level unless there is a clear overall policy on what direction we would like the Canadian forest sector to go or the direction the Canadian forest sector is forced to go.

- It is illustrated that a major policy change in one country can trigger actions in other countries, which will influence Canada's degree of freedom for actions.

\subsection{International Agreements}

There has been a rapid development of international agreements impacting forestry and the forest sector. In 1999, Holmgren (1999) identified some 30 international agreements affecting the forest sector. However, these agreements are not consistent between each other and point in different directions. There is a high probability that this development will continue in the future. Future agreements or modifications of current agreements will be a result of the attitudes and values at stake by the international society. These values in place may change rapidly. Nilsson (1996) illustrates that in Europe the demands from society on forest areas for functions other than wood production increased by some $20 \%$ within a 10 -year period. At the same time the demand on areas for wood production decreased by some $15 \%$.

In this connection we cannot discuss all existing agreements, but will simply use climate change and the so-called Kyoto Protocol as an example.

Papodopol (2000) illustrates the development of temperature and precipitation in Ontario during the last 100 years (Figure 11). If this development continues or increases there will be direct impacts on the productivity and indirect impacts in the form of changed disturbances. 
And also, perhaps more important, with continued development in this direction the society will request strong mitigation actions against climate change (in spite of large uncertainties with respect to causes of the climate development). Forestry will play a very important role in such a setting.

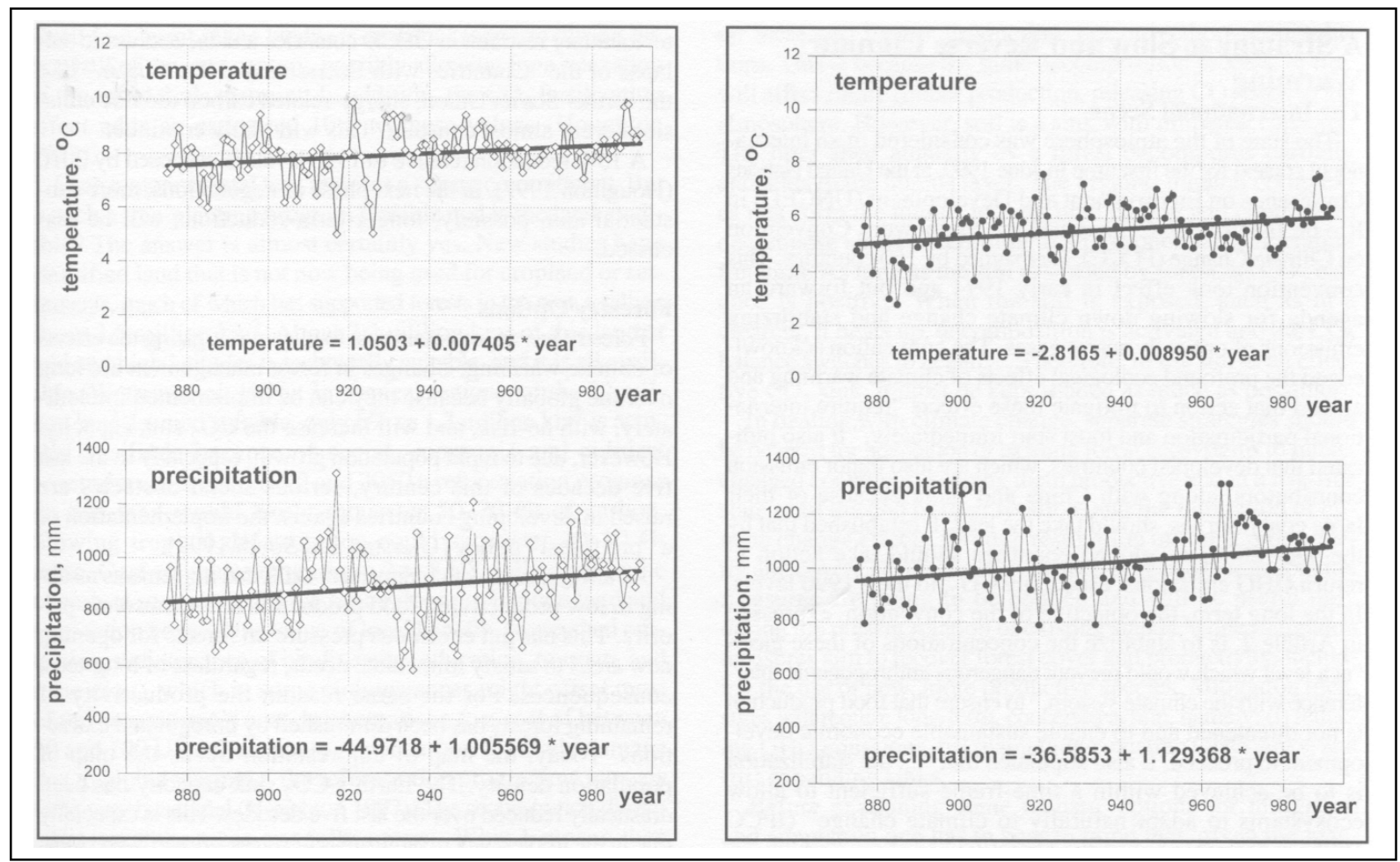

Figure 11: The development of temperature and precipitation over the last 100 years for Port Dover (left) and Parry Sound (right), Ontario (Papadopol, 2000).

Just after the adaptation of the Kyoto Protocol to the United Nations Framework Convention on Climate Change in December 1997, it was argued that this would be a major driving force for the development of forestry. For example, Brand (1998) argued "We are likely to see at least three trends following from the Kyoto Protocol in the forest sector - increase in plantation forests, increasing use of forest biomass as an energy source and a substitution of wood products for other, more energy intensive materials". So far, this has not really happened. The Kyoto Protocol limits the eligible actions to afforestation, reforestation and deforestation since 1990 and other vaguely defined "forest activities". The Kyoto Protocol is not ratified yet, which limits the implementation of the "trends flowing from the Kyoto Protocol" identified by Brand (1998).

At IIASA we have spent considerable time on the issue of carbon accounting and the Kyoto Protocol (Nilsson et al., 2000). The verifiability of carbon accounts will sooner or later become a necessary condition for the mutual recognition of legally binding commitments and will be even more important when it comes to carbon trading. The uncertainties are substantial in carbon accounting and the only possibility to identify these biases is to work with an ecosystem approach called Full Carbon Accounting. One consequence of this knowledge is that the Kyoto Protocol with respect to terrestrial ecosystems must have a quite different design compared to the current one. Thus, there will be a post-Kyoto development of the Protocol and what this design will look like is unknown in the current situation. 
With a continued change of the regional climate there will be a request for strong carbon management policies, which will require a new version of the Kyoto Protocol and new accounting rules. Based on our current knowledge, these new accounting rules will require a completely new set of criteria and indicators on sustainability, which will replace many of the existing ones.

\subsection{Post Mortem}

We have tried with the help of three examples, and in reality there are many more (currently known or unknown) factors or examples, to illustrate the need to link the implementation of criteria and indicators with overall development trends driven by forces outside the country. We argue that this link is missing today. Without this linkage we are working in a vacuum and do not really know if we are contributing to sustainable development by implementing criteria and indicators.

What is needed in order to achieve this linkage would be to work with broad objectives on what to achieve for the forest sector based on overall developments. The criteria and indicators should help to reach these objectives. In the current approach with criteria and indicators, the latter are used in a regulatory form on how to manage the forests instead of contributing to reaching the overall objective. Similar conclusions have been reached by Apsey et al. (2000) calling for an objective-oriented approach "with more focus on the broad results than defining how to manage".

\section{$4 \quad$ Criteria and Indicators and the Forest Planning Process from National to Local Levels: A Case Study}

Our discussion so far has focussed on general discussions around the criteria and indicators framework as a strategic tool for achieving sustainable forest management (SFM). In addition, this tool must be used for planning and carrying out actions in short-time frames that have long-term consequences for society and the environment. In our framework of Canadian Forest Management we categorize these management actions across the spectrum of strategic to tactical time scales and international to local spatial scales. We organize these actions into the following groups:

- An Institutional/Legislative framework supporting SFM.

- Planning Direction in the form of explicit social and economic needs from the forests is evaluated by using systems of criteria and indicators that must be supported by flows of information across this spectrum.

- Evaluation of Sustainability, by applying the SFM criteria and indicator framework and the sub-actions Information Collection and Reporting, is needed.

We evaluate the planning process' compatibility across management (spatial) and time scales. In particular, we investigate the constraints that higher-level (strategic) parts of the process place on lower level (tactical) components along with conflicts within the process.

Our conceptual overview of the application of criteria and indicators of sustainable forest management in Canadian forest management planning using Ontario as an example is presented in Figure 12. 


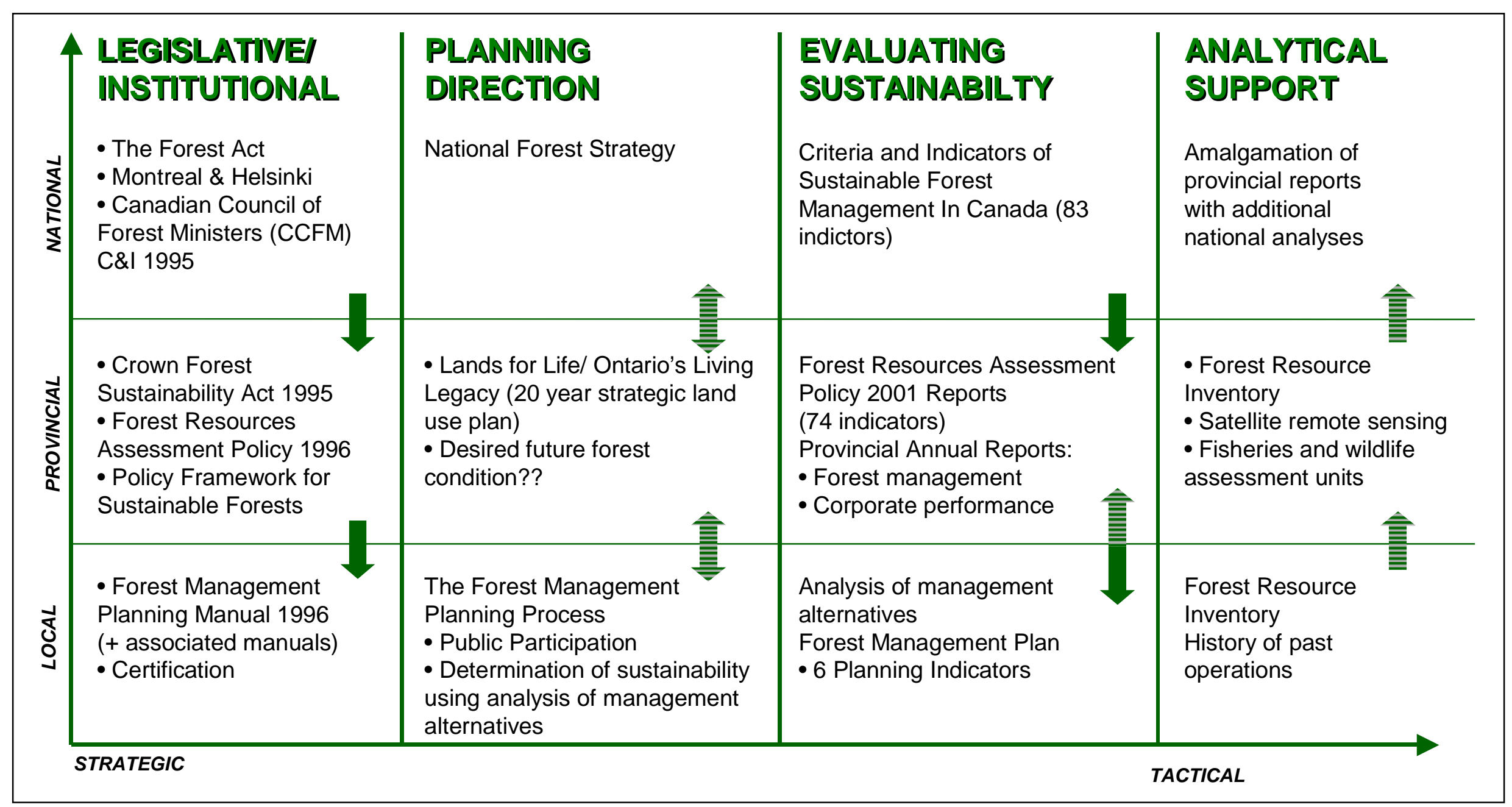

Figure 12: Overview of the application of criteria and indicators of sustainable forest management in Canadian forest management planning using Ontario as an example (arrows indicate the direction and relative content of information across administrative/spatial scales). 


\subsection{The Institutional/Legislative Framework}

There seems to be consensus that the institutional framework constitutes a major bottleneck for the sustainable development of a forest sector in many countries (Ljungman, 1998) and reforms are required in the forest administration and the policy framework. Ljungman (1998) claims that the main obstacle is the presence of powerful stakeholders with an interest in the status quo. At IIASA we have done a lot of work on the Institutional Framework in Russia (e.g., Carlsson et al., 2000 and Nilsson, 2000b) and we are of the opinion that there are limited possibilities for achieving sustainable development in this country without a dramatic change of the Institutional Framework. The Institutional Framework encompasses not only the formal structure of the organization of the sector, but also the sets of rules by which the sector is managed (Ostrom et al., 1994). Aspects of the Institutional Framework are coordination between forest sector organizations, legislation, property rights, tenure policies, revenue policies, land-use policies, transparency and reliability of information and data. Stiglitz (1999) claims that "Economic development and transition to something new is more a matter of institutional transformation than economic management".

Of course, we should not compare Canada with Russia or other similar countries on this issue, but we think that a general conclusion can be made from the above. The lesson is that with the change or transition toward a forest sector for sustainable development there is a strong need for change in the Institutional Framework. For example, if criteria and indicators introduced on how to carry out the management and required changes in the institutional framework are not carried through the possibilities for failure are rather high. Apsey et al. (2000) seem to be thinking along similar lines with respect to Canada and argue that in order to achieve sustainability reforms are needed in the policy framework, forest administration, tenure policies, revenue, planning process, policies, land-use policies, property rights and ownership.

At this occasion, we cannot address all aspects of the Institutional Framework in Canada, which is a rather complicated task. Therefore, in the following paragraphs we will try to illustrate one of the aspects, namely the planning process connected to the criteria and indicator approach in Ontario.

Apsey et al. (2000) claim that the existing regulatory system in Canada is "contentious, complicated and confusing, and, in many cases, incomprehensible". If this is the case the implementation of a new sustainability concept and a criteria/indicator system will face major difficulties. Facing this system are the group of actors in and around the forest that have expanded geographically and socially from local forest dwellers with a strong connection to nature to the international community who may never set foot in the forest they consider, in some part, theirs. In a recent Globe and Mail article, John Ralston Saul (2000) argued that the legal system in Canada, and the forest legislation is not outside of this problem, takes a "narrow corporatist approach; a world of consultants and of specialist dialects, of stakeholders and of confused, frustrated citizens". What is needed, he continues is to take the "enormous mound of law and regulation and administrative detail and to consolidate it; to clarify, boil down", to provide an arena for citizens to participate in the democratic process. 


\subsection{Planning Direction - What is the Future Forest Condition?}

As discussed earlier, Canadian forest management, along with most of the rest of the world has readily adopted systems of criteria and indicators for forests. The purpose of this system is to provide a common understanding and scientific definition of SFM and to define, measure and report on the forest values Canadians want to sustain and enhance.

Planning direction is a product of goal setting that includes, among other activities, an inclusive process of stakeholder participation - more simply stated it involves knowing what we want. An explicitly stated goal for SFM should include a description of the desired future condition of the forests. This links back to our earlier discussion of the need to work with an objective-oriented approach taking overall development trends into account. Only once this has been done can a system of criteria and indicators be applied to determine how close management is guiding the system towards this goal.

\subsubsection{National Level}

At the national level (National Forest Strategy) this goal is somewhat ambiguous:

"Our goal is to maintain and enhance the long-term health of our forest ecosystems, for the benefit of all living things both nationally and globally, while providing environmental, economic, social and cultural opportunities for the benefit of present and future generations".

This goal represents a common starting point. As this Strategy is voluntary in nature, precisely how the objectives are achieved is largely up to the members of Canada's forest community - the provinces and forest management actors. These communities must develop their own public and measurable action plans in response to the Strategy and appropriate to their respective circumstances and capabilities. In short - although there is a national system of criteria and indicators, they are largely descriptive in nature used for monitoring and cannot be applied as planning indicators. There is no statement of a future forest condition to support the goal, although at this scale we are unsure what this statement should entail.

\subsubsection{Provincial Level - The Case of Ontario}

The next level in Canada's forest community is the provincial level. Signatories to the forest accord should have developed a public and measurable action plan in 1998. As an example, in Ontario this plan is called the Forest Resource Assessment (FRAP) on Crown Lands in Ontario (Ontario Ministry of Natural Resources, 1997). The FRAP does four things:

- Describes the current condition of the resource;

- Develops specific objectives and associated future forest conditions towards which management efforts should be directed;

- Demonstrates progress in achieving forest sustainability by reporting on national criteria, indicator of sustainability; and 
- Evaluates the results of forest practices over the five-year term to assess consistency with the desired future forest condition.

What we like about this framework is that it makes explicit reference to an objectiveoriented approach or planned future condition. What concerns us is how this desired future forest condition is determined. Nowhere in the policy are the conditions or developments or a method for scenario development discussed.

Ontario accomplished an ambitious land use planning process called "Ontario's Living Legacy" in 1998 which:

...Developed a Strategy focusing on four specific objectives (completing a park's system, recognizing the land use needs of the resource-based tourism industry, providing forest, mining, and other resource industries with greater land and resource use certainty; and, enhancing angling, hunting and other Crown land recreation opportunities). The Strategy is a guidance document that sets a framework for future land and resource management on Crown lands in the planning area. It provides guidance and direction on what activities are proposed or preferred in certain areas and what activities will be permitted. This direction is primarily outlined through defining and locating land use categories that identify the general objectives, policies and uses for these areas. It also provides some general direction for resource management activities, as well as identifying a range of future planning and consultation needs (Ontario Ministry of Natural Resources, 1999).

This strategy, however, does not provide a picture of what the desired landscape in Ontario should look like in 20 years (this task has been delegated to Phase II of this process to determine Future Forest Conditions at sub-regional or ecoregional scales). Indeed, a review of the recommendations from the first phase of Land for Life process illustrates the avoidance of ecological issues in favor of viewing land use issues as a series of permitted or restricted uses determined by the strength of interest groups interestingly enough the opposite focus to that of the Canadian Council of Forest Ministers (CCFM) (see Section 4.2.1). The government has made post-process consultations with interest groups to make alterations to the recommended land use designations (e.g., increasing protected areas, modifying hunting restrictions). As mentioned earlier, the Ontario Ministry of Natural Resources (OMNR) must develop interim goals, objectives and targets for the 2001 FRAP. This task will be accomplished outside the public participation arena - and with limited direction from the land use strategy.

\subsubsection{Local Level}

Finally, at the management unit level, the forest management plan establishes the longterm strategic direction for managing the forest in order to achieve the desired future condition of the forest. That condition may be similar to the current forest condition or very different. The planning direction is influenced by:

“...the long-term strategic direction for managing the forest including legislation, OMNR policy and regional strategies, resource management (or other) issues on the management unit, and the current state of the 
forest. These factors, along with the benefits that are desired from the forest and the values that require protection, are considered by the planning team and the local citizens committee in the development of management objectives and strategies for the management unit".

The forest management planning process determines forest sustainability for the forest management unit. This is an adaptive management process in which different management alternatives are evaluated through an analysis of management alternatives. This process also incorporates public participation through the inclusion of local citizen committees. What concerns us is the apparent lack of coordination between the adaptive process at this scale with the provincial scale strategic planning.

\subsection{Evaluating Sustainability}

In 1995, a group of researchers at IIASA concluded "something is sustainable if it is what I like". In a sense this means a reversal of the current practice of monitoring a set of management-based indicators without knowing the desired goal — "what I like" is the goal or desired future forest products. Indicator levels are a quantification of this value statement that allows us to measure our progress in getting what we like. Currently, however, these indicators are applied unequally across administrative/spatial scales and this caused problems in adoption, measurement, synthesis and evaluation (Figure 4).

Nationally, 63 indicators are reported on a five-year basis, the first report appearing in 1997 and the next due in 2001. However, Canada does not translate these indicators into goal levels. In reality they are roll-ups of provincial programs, with some exceptions such as indicators of global ecological cycles.

At the provincial scale (Ontario), 74 indicators are in the process of being applied for FRAP 2001. The evaluation framework is not currently available. The 1996 FRAP (accomplished prior to criteria and indicators being enshrined in the forest management lexicon) employed six assessment measures:

- Forest Condition;

- Industrial Demand for Timber;

- Available Timber Supply;

- Silvicultural Investment Requirements;

- Areas of Potential Wildlife Habitat; and

- Forest Diversity.

At the management scale measurable indicators for biodiversity and multiple benefits to society are used in predictive models to estimate the effects of various management alternatives on these sustainability indicators. For biodiversity these indicators are:

- Landscape pattern;

- Frequency distribution of clear cut and wildfire sizes; and

- Forest diversity. 
Sustainability is assessed for these indicators by ensuring that levels are maintained within the bounds of natural variation - this itself is a major challenge for science from management organizations.

Whereas, multiple benefits to society are evaluated using the following indicators:

- Managed Forest Area;

- Percent of Available Harvest Area which is actually utilized; and

- Habitat for selected wildlife species.

As discussed in Section 4.2.2, once future forest condition(s) and quantified indicator levels are quantified they must be brought together in some meaningful way. This is best presented through a scenario itself. All of the possible management activities result in one indicator falling below the acceptable level. This becomes a task for society what trade-off is society willing to make in terms of a biodiversity indicator in order to keep an economic indicator at a level that benefits parts of society? Is it a flaw within the criteria and indicator process that results in having to compare separate parts of a complex system?

\subsubsection{Conflicts between Criteria and Indicators}

By studying the CCFM Criteria and Indicators we can identify that there are conflicts between the indicators used for ecology, between indicators used for economy, as well as between the indicators used for ecology respectively economy. These conflicts are illustrated in Figures 13-15. In the first illustration we can, for example, see that a high Forest Diversity Index causes a lower NPP or Growing Stock Indexes. The illustrations in Figures 13-15 are only examples of some of the existing conflicts in the current set of indicators. The key question is who is going to solve these conflicts between indicators? It is our determined opinion that these conflicts cannot be handled at international, national or regional level. The conflicts have to be solved at the local level. Based on this illustration we also think it is fair to raise the question of whether the current approach and set of criteria and indicators will guide us at all with respect to A Forest Sector for Sustainable Development? Aren't we back to square one? 


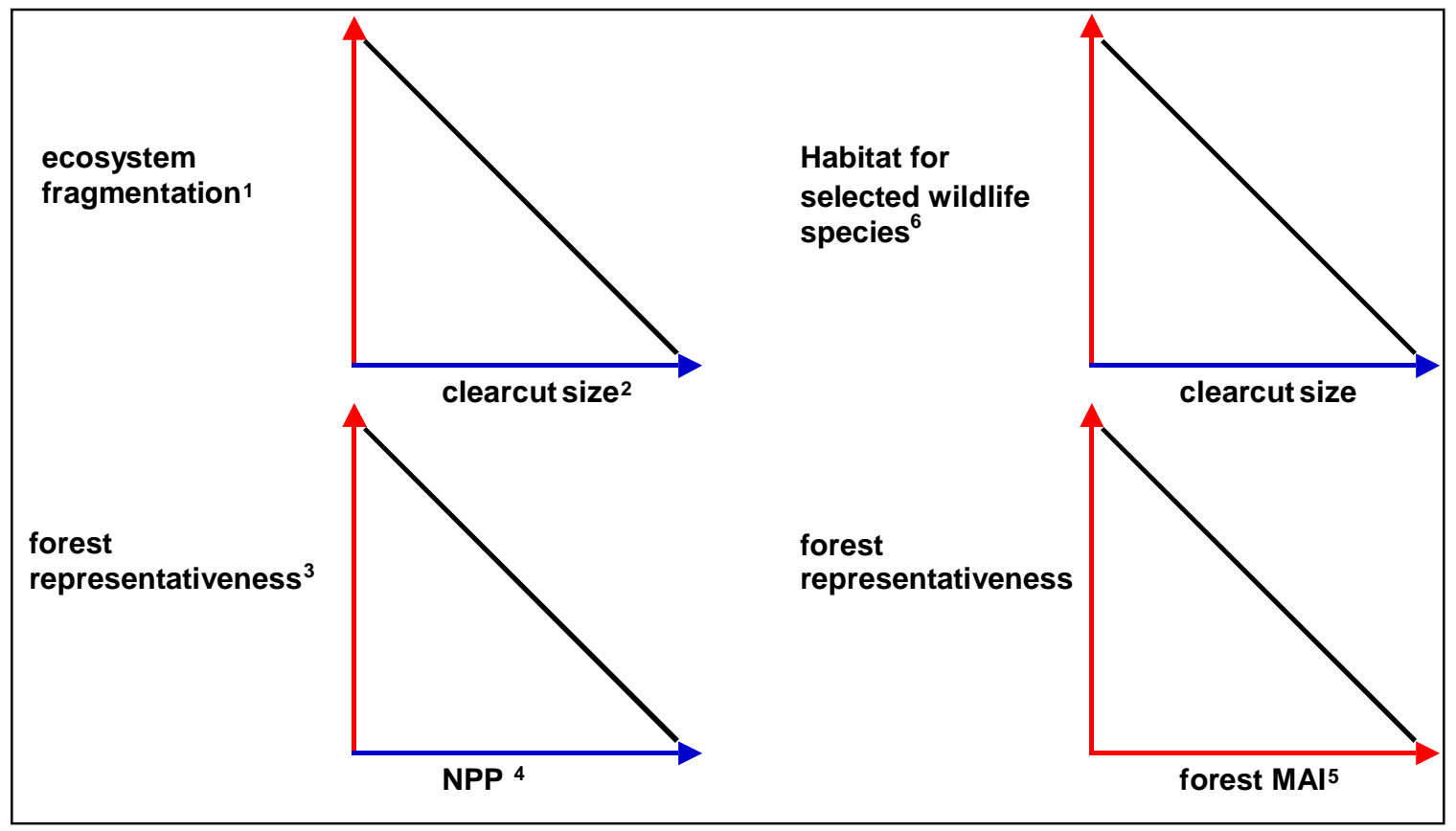

${ }^{1}$ CCFM indicator 1.1.4.

${ }^{2}$ From Ontario forest management planning manual. ${ }^{3}$ CCFM indicator 1.1.3.

${ }^{4}$ From Ontario forest management planning manual ${ }^{5} \mathrm{CCFM}$ indicator 2.3.1

${ }^{6}$ From Ontario forest management planning manual - in particular those species requiring larger tracts of homogeneous habitat may be adversely affected by smaller harvest areas distributed over larger areas.

Figure 13: Trade-offs between ecological indicators of sustainability.

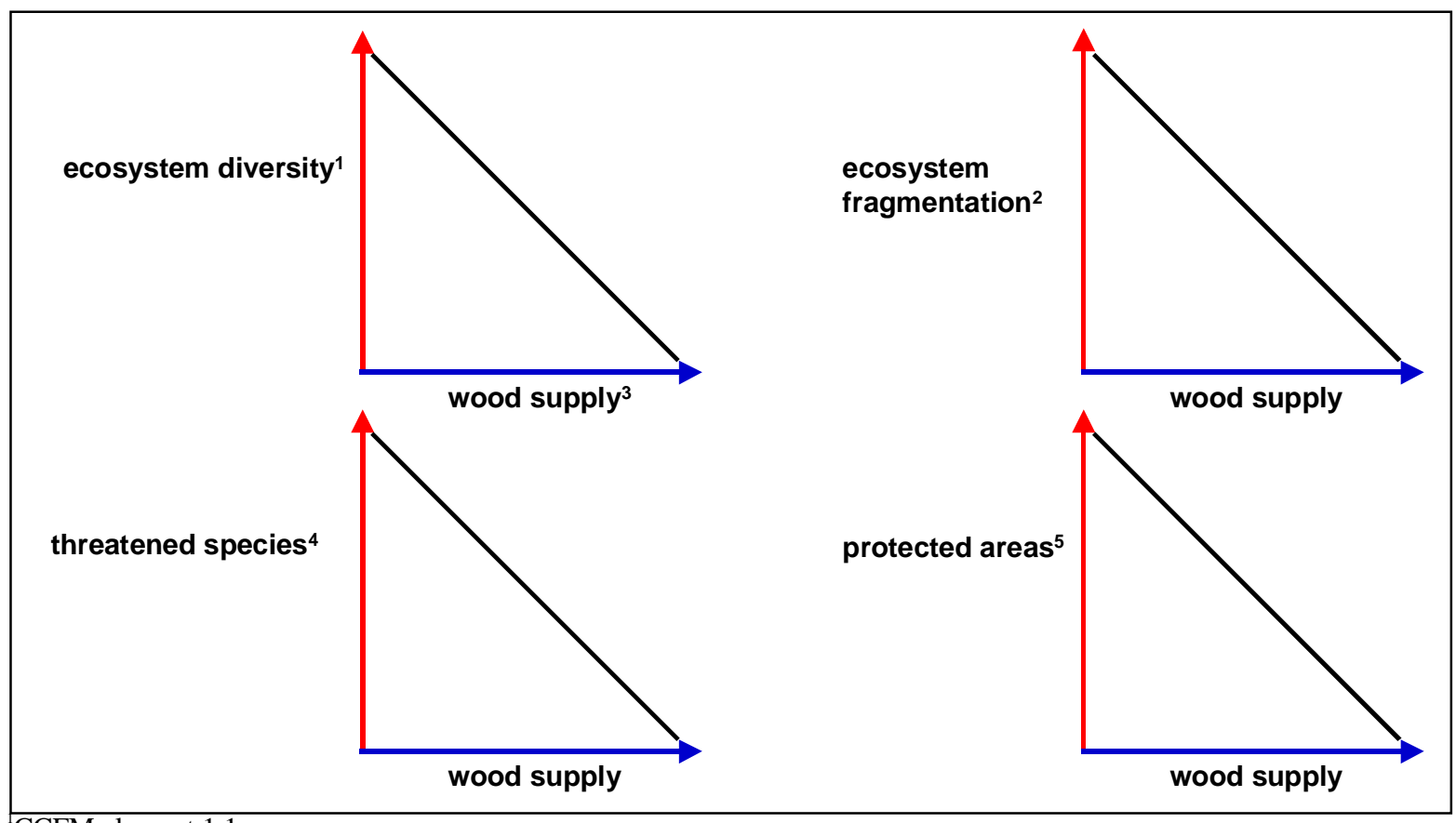

CCFM element 1.1.

${ }^{2} \mathrm{CCFM}$ indicator 1.1.4.

${ }^{3}$ From Ontario forest management planning manua.

${ }^{4} \mathrm{CCFM}$ indicator 1.2.1.

${ }^{5} \mathrm{CCFM}$ indicator 1.1.3.

Figure 14: Trade-offs between ecological and economic indicators of sustainability. 


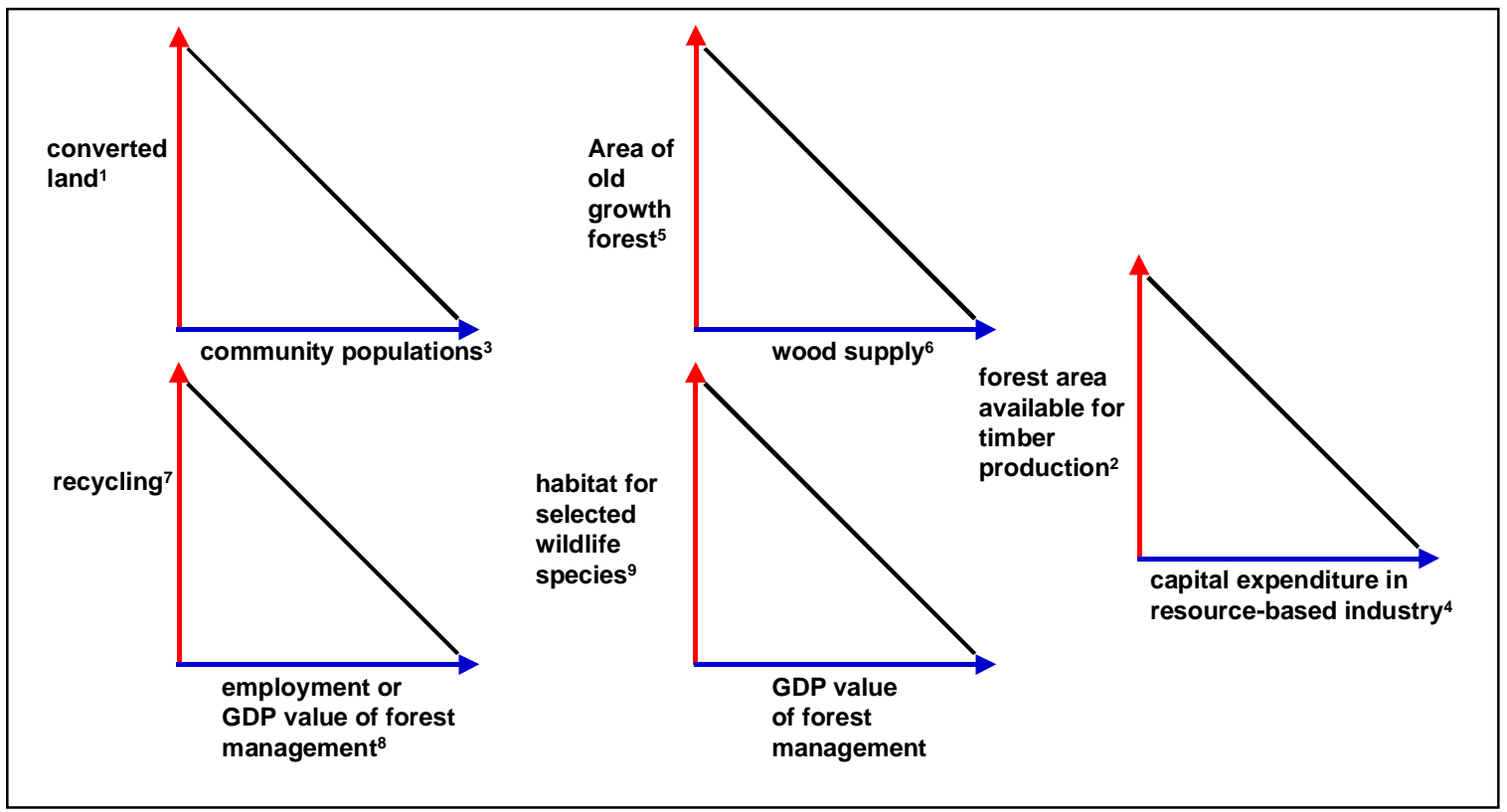

${ }^{1}$ CCFM element 4.2 .

${ }^{2} \mathrm{CCFM}$ indicator 5.1.2.

${ }^{3}$ From Ontario forest resource assessment.

${ }^{4}$ Duinker (2000).

${ }^{5}$ Duinker (2000).

${ }^{6}$ From Ontario forest management planning manual.

${ }^{7}$ CCFM indicator 4.4.1.

${ }^{8} \mathrm{CCFM}$ element 5.3.

${ }^{9} \mathrm{CCFM}$ indicator 5.1.5.

Figure 15: Trade-offs between ecological, economic and social indicators of sustainability.

\section{Analytical Support: Information Collection and Distribution}

We have illustrated that the current system of criteria and indicators has been driven by overall international agreements based mainly on negotiations. However, it has not been demonstrated how or how much these indicators contribute to sustainable development. Only when this is done can conflicts between indicators of the type discussed in the previous section be approached.

In Section 3 we have illustrated the lack of analysis dealing with the platform for sustainable development, namely analysis of the impact of the overall development trends, mainly driven by international trends. We argue that this has always been a Canadian bottleneck. But now it is high time to develop this analytical framework for an objective-oriented approach setting concrete targets. Without this framework the criteria/indicator approach is probably a lame duck and in reality will not contribute much to A Forest Sector for Sustainable Development. 
This new framework requires, as an action item, effort to identify, collect and distribute the information required to support SFM - specifically we focus on the information required to measure the sustainability indicators. The framework we have described is complex and within it the information generally flows upwards from local to national scales.

At the Management Unit level, four of the six planning indicators are directly measured from Forest Resource Inventory (FRI). A report (Duinker et al., 1997) to the Lake Abitibi Model Forest identified the numerous pitfalls of using FRI for spatial analysis of biodiversity (pattern and diversity) indicators. Analysis of wildfire patterns requires long-term ecological data that is often poorly maintained, if available, in most management units. Habitat models, among others, based on FRI are sensitive to the accuracy of the FRI. This fundamental information source has not been comprehensively reviewed for its ability to serve all of its current applications.

Ontario has 74 indicators, 18 of which are measured from the FRI at the provincial level and have the same caveats as mentioned above, but only 6 indicators are measured at the local level. At the provincial level, the government has two roles - to roll-up management unit information and to assemble other data in order to measure indicator commitments. Issues also include data ownership, harmonization and aggregation issues.

At the national level, we have earlier identified problems with respect to wood supply calculations/summaries (Nilsson et al., 1999). New initiatives seem to be aimed at dealing with these latter issues; specifically the CCFM's Canadian Forest Inventory Committee and the National Forestry Database.

\section{What To Do?}

We think, in general, that the current static system of criteria and indicators on sustainability does not really contribute to the development of a forest sector for sustainable development. The system concentrates on the management aspects instead of the objectives' setting. It is too complicated to be implemented and neglects the fact that sustainability cannot be achieved by a top-down approach but only by the people working on the ground at the local level (Nilsson, 2000a).

In order to move towards a forest sector for sustainable development we think:

- The major brain efforts should be made in setting the objectives/targets for the future development of the forest sector with respect to ecology, economy and societal aspects; and not on the management aspects;

- The process of target setting must observe international developments and consider how changes in markets, industry practices and environmental agreements affect local management actions;

- In order to make this possible Canada has to develop a new Analysis Framework for setting the objectives;

- The implementation of sustainability takes place on the ground at the local level and it is only at this level that real sustainability can be created and defined; 
- The local actors have to be informed and educated about the overall objectives/targets and development trends in order to place themselves in this framework. Our experience is that well-educated people knowing their position will take the necessary steps for a sustainable development;

- The local actors have to work with a system for sustainable development, which is operational and possible to handle;

- We think the reward system for the local actors within this system is the fact that they are able to place themselves in the overall development framework and develop their own future;

- In order to achieve this development there is a need to reform the existing Institutional Framework in Canada. In this reform work there is a strong need to identify the roles and obligations of the federal, provincial, regional and local scales to achieve A Forest Sector for Sustainable Development; and

- The forest sector has been weak in communicating with the rest of society. The new framework requires an efficient stakeholder dialogue based on the triple bottom line of ecological, economical and social sustainability. Without this the goodwill of the sector will be lost. 


\section{References}

Apsey, M., D. Laishley, V. Nordin and G. Paillé (2000). The Perpetual Forest: Using Lessons From the Past to Sustain Canada's Forests in the Future. The Forestry Chronicle, Vol. 76, No. 1:29-53.

Bazett, M. (2000). Long-Term Changes in the Location and Structure of Forest Industries. Paper presented at The World Bank/WWF Alliance/Council on Foreign Relations Global Vision Research Project, 15 January 2000, Washington, D.C., USA.

Behan, R.W. (1997). Scarcity, Simplicity, Separation — and Systems. In: K.A. Kohn and J.F. Franklin (eds.) Creating a Forestry for the $21^{\text {st }}$ Century: The Science of Ecosystem Management. Island Press, Washington, D.C., USA.

Binkley, C. S. (1997). Preserving Nature Through Intensive Plantation Forestry: The Case for Forest Land Allocation with Illustrations from British Columbia. Forest Chronicle, 73: 553-559.

Bull, G. (2000). Macro Trends in Fibre Supply. Paper presented at The World Bank/WWF Alliance/Council on Foreign Relations Global Vision Research Project, 15 January 2000, Washington, D.C., USA.

Brand, D. (1998). Opportunities Generated by the Kyoto Protocol in the Forest Sector. The Commonwealth Forestry Review, Vol. 77(3), September.

Brown, C. (1999). Global Forest Products Outlook Study. Thematic Study on Plantations. FAO, Rome, Italy.

Carlsson, L., N.-G. Lundgren and M.-O. Olsson (2000). Why is the Russian Bear Still Asleep After Ten Years of Transition? Interim Report IR-00-019. International Institute for Applied Systems Analysis, Laxenburg, Austria.

CSA (1996). A Sustainable Forest Management System: Guidance Document CAN/CSA-Z808-96, Environmental Technology: A National Standard for Canada, Canadian Standards Association (CSA), Etobicoke, Ontario, Canada.

Duinker, P.N. (2000). Personal communication.

Duinker, P.N. (ed.) (1997). Landscape analysis of boreal forests: Case studies on the lake Abitibi model forest, Ontario, Project Final Report to the Lake Abitibi Model Forest. Chair in Forest Management and Policy, Faculty of Forestry, Lakehead University, Thunder Bay, Ontario

Duinker, P.N., S. Nilsson and M.E. Chipeta (1998). Forestry for Sustainable Development and Global Fibre Supply. Unasylva, Vol. 49, No. 193:3-10.

Etzioni, A. (1968). The Active Society. A Theory of Societal and Political Processes. Free Press, New York, USA. 
FAO (1997) FAO’s Strategic Plan for Forestry, FAO, Rome, Italy.

Fleishman, S., J. Eastin and S. Shook (1999). Material Substitution in the U.S. Residential Construction Industry, Working Paper WP-73, CINTRAFOR, University of Washington, Seattle, WA, USA.

Hagler, R.W. (1999). The Global Timber Supply/Demand Balance to 2030: Has the Equation Changed? Wood Resources International, Reston, Virginia, USA.

Heilig, G.K. (1997). Sustainable Development - Ten Arguments Against a Biologistic "Slow-down" Philosophy of Social and Economic Development. The International Journal of Sustainable Development and World Ecology, Vol. 4, No. 1.

Holmgren, L. (1999). International Conventions and Other Instruments Dealing with International Forestry. The Royal Swedish Academy of Agriculture and Forestry Journal, 138:14 (in Swedish).

Kardell, L. (1995). Forest Management - Each Period of Time Has Its Own Counsels. In: Skogsåret, Skogsägarna, Stockholm, Sweden (in Swedish).

Ljungman, L. (1998). Economic Issues in Forestry. Paper presented at the Asia Development Forum, March 1998, FAO, Rome, Italy.

McIntyre, B. (2000), A View to the Future - Forestry in the New Millenium. The Forestry Chronicle, Vol. 76, No. 1:105-107.

Nilsson, N.-E. (1991). Forestry for Sustainable Development. Statement at the ITTO Council, May 1991, ITTO, Yokohama, Japan.

Nilsson, S. (2000a) Challenges for the Boreal Forest Zone and IBFRA. In: Susan G. Conard (ed.) Disturbance in Boreal Forest Ecosystems: Human Impacts and Natural Processes; International Boreal Forest Research Association 1997 Annual Meeting Proceedings, 4-7 August 1997, Duluth, Minnesota, USA. General Technical Report NC-209, U.S. Department of Agriculture, Forest Service, North Central Research Station, 300 pp. (in press).

Nilsson, S. (2000b). International Cooperation for Sustainable Development of the Russian Forest Sector. In: Final Report and Proceedings of the Expert Seminar "Sustainable Development of the Forest Sector in Northern Europe." Petrozavodsk, Russia, 12-13 October 1999. The Barents Region Forest Sector Initiative of the Barents Euro-Arctic Council/Working Group on Economic Cooperation, pp. 35-46, ISBN 951-708-858-2.

Nilsson, S. (1996). Do We Have Enough Forests? IUFRO Occasional Paper, No. 5, February, ISSN 1024-414X.

Nilsson, S., R. Colberg, R. Hagler and P. Woodbridge (1999). How Sustainable Are North American Wood Supplies? Interim Report IR-99-003. International Institute for Applied Systems Analysis, Laxenburg, Austria. 
Nilsson, S., A. Shvidenko, V. Stolbovoi, M. Gluck, M. Jonas and M. Obersteiner (2000). Full Carbon Account for Russia. Interim Report IR-00-021. International Institute for Applied Systems Analysis, Laxenburg, Austria (forthcoming).

Nowak, M.A., R.M. May and K. Sigmund (1995). The Arithmetic of Mutual Help. Scientific American, 272(6).

Obersteiner, M. and S. Nilsson (2000). Strategic Implications of eCommerce for Papermakers. Interim Report IR-00-016. International Institute for Applied Systems Analysis, Laxenburg, Austria.

Oliver, C.D. (1999). The Future of Forest Management Industry: Highly Mechanized Plantations and Reserves or a Knowledge-intensive Integrated Approach. The Forestry Chronicle, Vol. 75, No. 2.

Ontario Ministry of Natural Resources (1999). Ontario's Living Legacy, Approved Land Use Plan. (URL: http://www.mnr.gov.on.ca/MNR/oll/ALUS/).

Ontario Ministry of Natural Resources (1997). An Assessment of Ontario's Forest Resources 1996. Forest Report Series, Queen's Printer for Ontario.

Ostrom, E., R. Gardner and J. Walker (1994). Games and Rules and Common Pool Resources. University of Michigan Press, Ann Arbor, Michigan, USA.

Papadopol, C.S. (2000). Impacts of Climate Warming on Forests in Ontario. Options for Adaptation and Mitigation. The Forestry Chronicle, Vol. 76, No. 1:139-149.

Price Waterhouse Coopers (1999). The Primary Forest Products Industry in Ontario, 1998. Price Waterhouse Coopers, Canada.

Saul, J.R. (2000). How We Will Make Canada Ours Again? The Globe and Mail, 24 March.

Schelling, T. (1966). Arms and Influence. Yale University Press, New Haven and London.

Seip, H.K. (1996). Forestry for Human Development: A Global Imperative. Scandinavian University Press, Oslo, Norway.

Spears, J. (2000). Summary of Main Findings Emerging from Phase 1: And Their Implications for Further Research. Paper presented at The World Bank/WWF Alliance/Council on Foreign Relations Global Vision Research Project, 15 January 2000, Washington, D.C., USA.

Stiglitz, J.E. (1999). Whither Reform? Ten Years of the Transition. Keynote Address at The World Bank “Annual Conference on Development Economics," 28-30 April 1999, The World Bank, Washington, D.C., USA.

Whiteman, A. and C. Brown (1999). The Potential Role of Forest Plantations in Meeting Future Demands for Industrial Wood Products. International Forestry Review, Vol. 1, No. 3. 